\title{
Social disparities among youth and the impact on their health
}

This article was published in the following Dove Press journal:

Adolescent Health, Medicine and Therapeutics

26 March 2015

Number of times this article has been viewed

\section{Catherine Kreatsoulas ${ }^{1, *}$ \\ Areej Hassan ${ }^{2, *}$ \\ SV Subramanian' \\ Eric W Fleegler ${ }^{3}$ \\ 'Department of Social and Behavioral Sciences, Harvard School of Public Health, Boston, MA, USA; ${ }^{2}$ Division of Adolescent/Young Adult Medicine, Boston Children's Hospital Boston, Boston, MA, USA; ${ }^{3}$ Division of Emergency Medicine, Boston Children's Hospital Boston, Boston, MA, USA \\ *These authors contributed equally to this work}

Purpose: Social disparities among youth have been recognized as an important influence on disease risk later in the life cycle. Despite this, social problems are seldom assessed in a clinical setting. The primary objective of our study was to evaluate the impact of social disparities on the health of youth.

Methods: A self-directed, web-based screening system was used to identify social disparities along seven social domains. Participants included youth, aged 15-24 years, recruited from an urban hospital clinic. The main outcome variable, self-rated health, was captured on a 5-point Likert scale. Univariable and multivariable regression models adjusted for sex, age, and race/ethnicity were implemented to assess the association between social problems and self-rated health. Correlation between social disparity problems was estimated using phi coefficient.

Results: Among 383 participants, 297 (78\%) reported at least one social problem. The correlation among social disparity problems was low. Social disparities had an independent effect on self-rated health, and, in a fully adjusted model, disparities in health care access and food insecurity remained significant. The presence of even one social problem was associated with a decrease in overall health $(\beta=0.68, P<0.01)$.

Conclusion: There is a high burden of social disparities among our youth urban hospital population. The presence of even one social problem increases the risk of worsening self-rated health. Evaluating the social disparities among youth in the medical setting can help elucidate factors that negatively affect patients' health.

Keywords: social determinants of health, self-rated health, social problems, clinical setting

\section{Introduction}

The young in our society are often perceived to be in the "healthiest" stage of life, and, as a result, there has been a smaller public health focus on improving the overall health of youth. "Youth" is a term used to describe a period in the human life cycle that pertains to young females and males, aged 15 to 24 years, to reflect the stage of biological maturation changes, cognitive development, and transition period of social roles. ${ }^{1,2}$ Although biological maturation and cognitive changes are well known and relatively consistent across youth, there are variations in the social role changes and pressures among youth. Therefore, in order to gain a deeper understanding of the health of youth, it is imperative to examine the social environment in which they live. The social determinants of health, which are defined as "the conditions in which people are born, grow, live, work and age", ${ }^{3}$ focus on the social context that affect health and pathways in which social conditions translate to health effects. ${ }^{4,5}$
Correspondence: Catherine Kreatsoulas Department of Social and Behavioral Sciences, Harvard School of Public Health, I I 37 Massachusetts Ave (37), Cambridge, MA, 02138, USA Email ckreats@hsph.harvard.edu 
There is growing recognition of the need to systematically measure the social determinants of health among youth to increase their visibility, while separating youth issues from those of adults.

The long-term effects of poor social circumstances early in life have been widely recognized as influencing disease risk later in adulthood. ${ }^{6}$ Life course epidemiology seeks to elucidate exposures and their relationship to health across the different stages in an individual's life. ${ }^{7}$ There is increasing recognition that the social problems that impact youth health can have long-term effects later in the life course. ${ }^{8-11}$ Further, the social problems that affect youth are not static, and the social environments that youth experience today vary substantially compared to birth cohorts of the past 30 years in the United States..$^{10}$

Youth experience a broad range of social disparities that can deleteriously affect aspects of their health. While the leading causes of hospitalization among youth include mental disorders, injury, and respiratory issues, problems such as poor housing, interpersonal violence, and food insecurity impinge on the health and development of youth and are associated with increased hospitalization rates, increased emergency department use, and postponed medical care. ${ }^{12-16}$ Despite the recognized importance of social problems on health, most studies that investigate such social disparities assemble data that were not originally collected for this purpose, investigate one or only a few social problems at a time, use aggregate level data that fail to represent the individual experience, and are often laden with inherent methodological issues related to retrospective study designs. At the same time, there has been a slow translation of knowledge incorporating screening of social problems in a clinical setting despite its recognized importance. Further, the impact of social problems on individual perceptions of health, particularly during the youth stage of the life course, has seldom been addressed.

To understand the impact of social disparities on youth health, we designed and implemented a comprehensive screening of social problems among youth seeking care at a Boston-area (MA, USA) primary care urban hospital. We hypothesized that individuals with more social problems would have worse self-rated health, and therefore the objectives of our study included: 1) assessment and determination of the association of social problems with self-rated health among our youth population, and 2) estimation of the correlation between categories of social problems.

\section{Methods}

The study received ethics approval by the Boston Children's Hospital institutional review board, consistent with guidelines for youth research.

\section{Study participants and study setting}

The study methods have been previously published ${ }^{17,18}$ and are summarized in brief herein. Youth seeking care at Boston Children's Hospital's young adult clinic were eligible to participate in a study using The Online Advocate, a selfdirected, web-based screening and referral tool for social problems. The clinic is a primary care facility providing care to over 5,000 unique primary care patients annually from the surrounding communities; approximately onethird of the clinic patients receive their health insurance coverage through Medicaid. To recruit patients into the study, a research recruitment flag for this study, along with other studies, was attached to the appointment paperwork of age-eligible patients. Providers were asked to approach patients for entry into the study, and those who were interested were referred to a clinic resource specialist, a staff member trained to facilitate referrals to social services and to provide more detailed information. Study participants were logged onto a laptop computer equipped with a privacy screen, and the clinic resource specialist remained available to assist with any technical difficulties. Patient recruitment occurred from December 2008 to August 2010.

\section{Inclusion/exclusion criteria}

Eligible participants were aged 15 to 24 years and seeking care from a medical provider at the primary care clinic at Boston Children's Hospital. Participants were excluded from the study if they had a disability or developmental delay that would interfere with their ability to comprehend and complete the questionnaire at the time of their visit. Ability to read English was required. All patients provided written informed consent or assent. Patients under age 18 years were granted a waiver of the requirement of parental consent to participate.

\section{The Online Advocate}

Details of the development of The Online Advocate are published elsewhere. ${ }^{17}$ Briefly, The Online Advocate was developed primarily to screen patients for social problems, to identify desired social needs, and to assist in the referral process to appropriate social services. The questionnaire consisted of 90-130 questions, written at a grade 5 to 6 comprehension level (Flesch-Kincaid). The questionnaire used branch logic to determine question sequence. Participants had the option to skip questions they did not feel comfortable answering. A more recent version of the system can be accessed at http://www.HelpSteps.com. 
Questions were categorized under themes forming seven social domains, including: 1) education, 2) health care access, 3) income insecurity, 4) substance use, 5) food insecurity, 6) housing, and 7) interpersonal violence. Validated screens include the United States Department of Agriculture (USDA) food security scale ${ }^{19}$ to determine level of food insecurity, an adolescent substance abuse screening tool (CRAFFT) ${ }^{20}$ and the Growing Up Today Study (GUTS) ${ }^{21}$ to assess for problematic substance use,$^{20}$ and the American Housing Survey ${ }^{22}$ to determine housing hazard standards. Additionally, questions in the screening tool pertaining to education problems, health care access, income security, and interpersonal violence were derived from large, validated, national surveys, including the Youth Risk Behavior Survey (YRBS), ${ }^{23}$ the National Longitudinal Study of Adolescent Health (Add Health) ${ }^{24}$ the Behavioral Risk Factor Surveillance Survey (BRFSS), ${ }^{25}$ and a specialized validated interpersonal violence screening tool. ${ }^{26}$ Responses to questions were used to identify and/or quantify problems within each domain. A list of the potential problems that compose each domain can be found in Table S1.

We measured the self-rated health of each participant as a linear variable using a 5-point Likert scale; participants were asked the well-validated question, "In general, would you say your health is $1=$ excellent, $2=$ very good, $3=$ good, $4=$ fair, or $5=$ poor? ${ }^{\prime 27,28}$ We could not calculate a negative refusal rate, as the chart-flagging recruitment system did not collect data about which of the providers spoke to patients about participation. However, a total of 444 participants expressed interest in the study, of which $401(90 \%)$ consented and completed the study. The participants that dropped out did not differ significantly in sex, age, or race/ethnicity compared to the study population. Further, the demographics of our final sample were similar to the overall clinic population with respect to age, sex, and race/ethnicity and likely represent a cross-section of the clinic population.

\section{Statistical considerations}

Demographic characteristics including sex, age, and race/ ethnicity were obtained. The distributions of social problems were analyzed according to social problem domain and summarized according to sex. Continuous variables were compared using $t$-tests and analysis of variance (ANOVA), and dichotomous variables were compared using chi-square tests. To determine the correlation between social problems, which were captured as present $=1$, absent $=0$, phi coefficient was estimated. Mean self-rated health was calculated according to sex, race/ethnicity, and social problem domain. Unadjusted univariable regression models assessed the independent relationship of the social problems with selfrated health. Social problems often do not occur in isolation, therefore we also constructed multivariable regression models (adjusted for sex, age, race/ethnicity) to assess the association between all the social problems with self-rated health. All tests employed two-tailed significance testing. All analyses were performed using JMP ${ }^{\circledR}$ Pro 10.0 (SAS Institute Inc., Cary, NC, USA) and IBM SPSS $20.0^{\circledR}$ (IBM Corporation, Armonk, NY, USA).

\section{Results \\ Demographic characteristics}

A total of 401 study participants completed the entire questionnaire, providing information about social factors and health. Specifically, 383 rated their health, including 118 males (31\%) and 265 females (69\%). Over one-half of the study participants (55\%) identified themselves as AfricanAmerican, and $30 \%$ as Hispanic; the mean ( \pm standard deviation) age of the study population was $\bar{X}=18.1 \pm 2.0$ years (Table 1).

\section{Correlation among social problem categories}

The degree to which categories of social disparities correlated with each other was low overall; statistically significant correlations ranged from $\varphi=0.10$ to $\varphi=0.23$. We found that screening positive for a problem within the education domain was correlated with all other social problem categories, ranging from $\varphi=0.10, P<0.05$ for health care access to $\varphi=0.22$, $P<0.01$ for substance abuse. With the exception of interpersonal violence, food insecurity was also correlated with screening positive for a problem in all other social domains (range $\varphi=0.14$ to 0.23 , all $P<0.01$ ). The strongest correlations with food insecurity included problems related to health care access $(\varphi=0.23, P<0.01)$, housing $(\varphi=0.23, P<0.01)$, and substance use $(\varphi=0.22, P<0.01)$ (Table 2$)$.

\section{The impact of social problems on self- rated health}

Females rated their overall health worse than males ( $\overline{\mathrm{X}}=2.79 \pm 1.03$ versus $\overline{\mathrm{X}}=2.55 \pm 0.87$, respectively $P=0.027$ ), while we found no statistically significant differences in self-rated health according to race/ethnicity and age. Youth that screened positive for any social problem rated their health significantly lower compared to those without a social problem, with the exception of interpersonal violence (all 
Table I Demographic characteristics and distribution of social problems among youth

\begin{tabular}{|c|c|c|c|c|c|c|c|}
\hline & \multicolumn{2}{|c|}{$\begin{array}{l}\text { Total population, } \\
\mathrm{N}=383\end{array}$} & \multicolumn{2}{|c|}{$\begin{array}{l}\text { Males, } \\
\mathrm{N}=118\end{array}$} & \multicolumn{2}{|c|}{$\begin{array}{l}\text { Females, } \\
\mathrm{N}=265\end{array}$} & \multirow{2}{*}{$\begin{array}{l}P \text {-value, } \\
\text { males versus } \\
\text { females }\end{array}$} \\
\hline & $\mathbf{N}$ & $\%$ & $\mathbf{N}$ & $\%$ & $\mathbf{N}$ & $\%$ & \\
\hline \multicolumn{8}{|l|}{ Demographic characteristics } \\
\hline Non-Hispanic White & 30 & 7.9 & 12 & 10.2 & 18 & 6.8 & 0.30 \\
\hline Hispanic & 113 & 29.5 & 24 & 20.3 & 89 & 33.6 & 0.44 \\
\hline Non-Hispanic African-American & 212 & 55.4 & 70 & 59.3 & 142 & 53.6 & 0.35 \\
\hline Other, non-Hispanic & 28 & 7.3 & 12 & 10.2 & 16 & 6.0 & 0.54 \\
\hline Mean age \pm standard deviation (years) & \multicolumn{2}{|c|}{$18.1 \pm 2.0$} & \multicolumn{2}{|c|}{$17.9 \pm 2.0$} & \multicolumn{2}{|c|}{$18.1 \pm 2.0$} & 0.27 \\
\hline \multicolumn{8}{|l|}{ Social problem } \\
\hline Education & 55 & 14.4 & 23 & 19.5 & 32 & 12.1 & 0.06 \\
\hline Health care access & 148 & 38.6 & 41 & 34.7 & 107 & 40.1 & 0.32 \\
\hline Income insecurity & 41 & 10.7 & 14 & 11.8 & 26 & 9.8 & 0.53 \\
\hline Substance abuse & 81 & 21.1 & 32 & 27.1 & 49 & 18.5 & 0.05 \\
\hline Food insecurity & 117 & 30.5 & 39 & 33.1 & 78 & 29.4 & 0.46 \\
\hline Housing & 135 & 35.2 & 44 & 37.3 & 91 & 34.3 & 0.54 \\
\hline Interpersonal violence & 62 & 16.2 & 17 & 14.4 & 45 & 17.0 & 0.55 \\
\hline At least one problem & 297 & 77.8 & 97 & 82.9 & 199 & 75.4 & 0.11 \\
\hline
\end{tabular}

Note: Values in bold are a design variable depicting the presence of any one of the above variables.

$P<0.05$, unadjusted). The range of self-rated health varied slightly among significant social problem domains (unadjusted self-rated health range $\overline{\mathrm{X}}=2.89$ to 3.04 ). Similarly, youth that reported at least one social problem rated their health lower compared to those that reported no social problems (unadjusted self-rated health $\overline{\mathrm{X}}=2.84,95 \%$ confidence interval $[\mathrm{CI}] 2.73-2.95$ versus $\overline{\mathrm{X}}=2.25,95 \% \mathrm{CI}: 2.04-2.45$, $P<0.001$, respectively) (Table 3 ).

In the univariable adjusted models, problems with education, health care access, substance use, food insecurity, and housing all had a significant negative impact on youth health. The social problems with the greatest impact on youth health included food insecurity, which decreased self-rated health by almost half a point on a 5-point scale (intercept $=2.20$, $\beta=0.49, P<0.001$ ), and health care access (intercept $=2.19$, $\beta=0.45, P<0.001$ ). Almost $40 \%$ of youth reported a problem with access to health care, which significantly worsened as age increased (data not shown). Furthermore, the presence of any one social problem negatively impacted youth health by $\beta=0.68$ points on a 5 -point scale $(P<0.001)$. In a fully adjusted multivariable regression model (sex, age, race/ ethnicity, and all social problems), the negative impact of disparities in health care access and food insecurity on selfrated health remained significant $(\beta=0.34, P<0.001$ and $\beta=0.32, P=0.004$, respectively) (Table 4).

\section{Discussion}

Our study demonstrates a substantial burden of social disparities among a diverse youth population screened in a clinical setting: $78 \%$ of youth screened positive for at least one social problem, with over one-third of the youth experiencing problems with health care access, housing, and food insecurity. We report a low correlation among the social problems, where they had a negative impact on the self-rated health of youth. Specifically, problems in the domains of health care access and food insecurity represented the strongest impact on youth health. It is concerning that screening positive for at least one social problem worsened self-rated health score by nearly three-quarters of a point on a 5-point scale. We flag this as an important issue, as often, little attention is given to

Table 2 Phi correlation of social problems

\begin{tabular}{|c|c|c|c|c|c|c|c|}
\hline & Education & $\begin{array}{l}\text { Health care } \\
\text { access }\end{array}$ & $\begin{array}{l}\text { Income } \\
\text { insecurity }\end{array}$ & $\begin{array}{l}\text { Substance } \\
\text { abuse }\end{array}$ & $\begin{array}{l}\text { Food } \\
\text { insecurity }\end{array}$ & Housing & $\begin{array}{l}\text { Interpersonal } \\
\text { violence }\end{array}$ \\
\hline Education & - & $0.10 *$ & $0.20 * *$ & $0.22 * *$ & $0.19 * *$ & $0.12^{*}$ & $0.16 * *$ \\
\hline Health care access & & - & 0.08 & $0.14 * *$ & $0.23 * *$ & $0.14 * *$ & 0.08 \\
\hline Income insecurity & & & - & 0.08 & $0.14^{* *}$ & 0.09 & 0.06 \\
\hline Substance abuse & & & & - & $0.22^{* *}$ & 0.00 & $0.15^{* *}$ \\
\hline Food insecurity & & & & & - & $0.23^{* *}$ & 0.08 \\
\hline Housing & & & & & & - & 0.02 \\
\hline Interpersonal violence & & & & & & & - \\
\hline
\end{tabular}

Notes: $* P<0.05 ; * * p<0.01$. 
Table 3 Unadjusted mean SRH score according to demographic characteristics and social problems

\begin{tabular}{|c|c|c|c|}
\hline \multirow{2}{*}{$\begin{array}{l}\text { Characteristic } \\
\text { Sex }\end{array}$} & \multicolumn{2}{|c|}{ SRH, mean $(95 \% \mathrm{CI})$} & \multirow{2}{*}{$\begin{array}{l}\boldsymbol{P} \text {-value } \\
0.027\end{array}$} \\
\hline & & & \\
\hline Males & $2.55(2.39-2.7 \mathrm{I})$ & & \\
\hline Females & $2.79(2.66-2.91)$ & & \\
\hline Race/Ethnicity & & & 0.167 \\
\hline Non-Hispanic White & $2.70(2.34-3.06)$ & & \\
\hline Hispanic & $2.86(2.68-3.04)$ & & \\
\hline Non-Hispanic & $2.67(2.54-2.81)$ & & \\
\hline African-American & & & \\
\hline Other, non-Hispanic & $2.42(2.04-2.80)$ & & \\
\hline Age & $2.28(1.34-3.23)$ & & 0.312 \\
\hline Social problems & $\begin{array}{l}\text { Social problem } \\
\text { present SRH, } \\
\text { mean }(95 \% \mathrm{Cl})\end{array}$ & $\begin{array}{l}\text { Social problem } \\
\text { absent SRH, mean } \\
(95 \% \mathrm{CI})\end{array}$ & \\
\hline Education & $3.00(2.72-3.29)$ & $2.66(2.56-2.77)$ & 0.021 \\
\hline Health care access & $3.01(2.85-3.16)$ & $2.53(2.4 I-2.66)$ & $<0.001$ \\
\hline Income insecurity & $3.00(2.74-3.26)$ & $2.68(2.58-2.79)$ & 0.051 \\
\hline Substance abuse & $2.91(2.7 I-3.12)$ & $2.66(2.55-2.78)$ & 0.042 \\
\hline Food insecurity & $3.04(2.85-3.23)$ & $2.57(2.46-2.68)$ & $<0.001$ \\
\hline Housing & $2.89(2.74-3.04)$ & $2.62(2.49-2.75)$ & 0.011 \\
\hline Interpersonal violence & $2.85(2.63-3.08)$ & $2.69(2.58-2.80)$ & 0.225 \\
\hline $\begin{array}{l}\text { At least one social } \\
\text { problem (versus none) }\end{array}$ & $2.84(2.73-2.95)$ & $2.25(2.04-2.45)$ & $<0.001$ \\
\hline
\end{tabular}

Note: Values in bold are a design variable depicting the presence of any one of the above variables.

Abbreviations: $\mathrm{Cl}$, confidence interval; $\mathrm{SD}$, standard deviation; $\mathrm{SRH}$, self-rated health.

the current self-rated health of youth, and more importantly it has been previously reporte $\mathrm{d}^{27-30}$ that the life course trajectory of self-rated health is known to decrease with age.

Our results demonstrate a somewhat surprising and unfortunate youth perspective; namely, a mean self-reported health score of 2.84 approaches "good" health. Society so often mistakenly assumes that youth should report overall "excellent" or at least "very good" health, as this time period has the lowest reported rates of morbidity and mortality across all age groups ${ }^{31}$ as well as the lowest health care expenditures. ${ }^{32,33}$
The results of our study challenge this perspective, as the majority of youth in our study reported a social problem, and we demonstrated that these social problems affect their selfassessment of health. Although we do not know the long-term prognosis for the youth in our study, we raise concern given this assessment so early in the life course. Self-rated health studies in adults demonstrate that the concept of self-rated health is a valid predictor of future health outcomes, as it captures the dynamic trajectory of health and not just the current health status of an individual at a defined point in time..$^{27,28}$ Despite limited literature on self-rated health among youth, studies indicate that, as youth transition to adulthood, earlier self-rated health scores correlate with their self-rated health as adults. ${ }^{29,30}$ Previous studies indicate that the self-rated health of youth is an enduring self-concept of their global health perception, which is stable over time and not just a spontaneous physical health assessment. ${ }^{29,30} \mathrm{~A}$ longitudinal study that measured the self-rated health of youth followed to adulthood reported a general trend that as age increases, self-rated health worsens. ${ }^{29}$ This information should be considered in a clinical setting; when screening for health-related social problems and other medical issues, providers should also consider discussing patients' self-rated health.

This study is important as it represents a translation of knowledge from social epidemiology into an application of comprehensive screening for social disparities in a clinical setting. The importance of incorporating social screening into a clinic visit has been demonstrated in earlier work; self-directed screening programs can lead to more time for focused discussions between patients and providers and an opportunity to link youth with available community social services. ${ }^{34}$ In addition to assisting with social problems, we directly asked youth in this study to assess their own health and demonstrated a significant relationship between social problems and their health.

Table 4 Linear regression models of the association of social problems on self-rated health

\begin{tabular}{|c|c|c|c|c|c|c|}
\hline \multirow[t]{2}{*}{ Social problem } & \multicolumn{3}{|c|}{ Univariable model $^{\mathrm{a}}$} & \multicolumn{3}{|c|}{ Multivariable model ${ }^{b}$} \\
\hline & Intercept (SE) & $\beta$-estimate (SE) & $P$-value & Intercept (SE) & $\beta$-estimate (SE) & $P$-value \\
\hline Intercept & & & & $2.28(0.48)$ & & $<0.001$ \\
\hline Education & $2.10(0.48)$ & $0.38(0.14)$ & 0.008 & & $0.17(0.15)$ & 0.25 \\
\hline Health care access & $2.19(0.48)$ & $0.45(0.10)$ & $<0.001$ & & $0.34(0.10)$ & $<0.001$ \\
\hline Income insecurity & $2.24(0.49)$ & $0.31(0.17)$ & 0.068 & & $0.17(0.16)$ & 0.310 \\
\hline Substance abuse & $2.20(0.06)$ & $0.28(0.13)$ & 0.029 & & $0.10(0.13)$ & 0.429 \\
\hline Food insecurity & $2.20(0.48)$ & $0.49(0.11)$ & $<0.001$ & & $0.32(0.11)$ & 0.004 \\
\hline Housing & $1.91(0.49)$ & $0.30(0.11)$ & 0.004 & & $0.17(0.11)$ & 0.104 \\
\hline Interpersonal violence & $2.07(0.49)$ & $0.15(0.14)$ & 0.263 & & $0.04(0.13)$ & 0.773 \\
\hline Any social problem & $1.81(0.47)$ & $0.68(0.12)$ & $<0.001$ & & & \\
\hline
\end{tabular}

Notes: aAdjusted for sex, age, and race/ethnicity; badjusted for sex, age, race/ethnicity and all social problems. Abbreviation: SE, standard error. 
In our current generation, youth represent a higher proportion of the total population than ever before, comprising one-quarter of the world's population. ${ }^{2}$ Although there are multiple factors that impact self-rated health, such as mental health problems, medical diagnoses, family support system, and health behaviors, the presence of social problems such as those screened for in our study also play a critical role. Screening, identifying, and addressing social problems at this stage of life can have multiple long-term implications, including potentially altering the dynamic nature of the socioeconomic status attainment during this development period, ${ }^{35}$ thwarting downstream health effects into adulthood and altering the life course. ${ }^{8,10,36}$

In this study, we demonstrated that a multitude of social problems are independently associated with self-rated health, and that the presence of even one social problem negatively affects self-rated health. Among the youth in our study with a high social problem burden, access to health care and food insecurity were most strongly associated with self-rated health. Our findings are consistent with those of other studies in which young adults faced greater barriers in access to health care, largely attributed to the loss of insurance as young people lose their parents' coverage and/or eligibility for public health care programs. ${ }^{37,38}$ This finding has direct implications for health, as it is well established that a lack of health insurance is associated with lower rates of primary care, dental visits, and fulfilled prescriptions and higher levels of unmet needs. ${ }^{37,38}$ Although recent national data suggest that health care coverage among young adults is slowly improving, ${ }^{39}$ we still found a significant problem with access to health care among our youth population, with a high social problem burden. In addition, we found that food insecurity, which was reported by almost one-third of the youth in our study, was strongly associated with poorer self-rated health, even when adjusted for all screened social problems. Access to nutritious food is especially critical during adolescence, a time during which youth experience significant brain development and growth. Further, food insecurity has been well associated with more frequent illness, poor educational outcomes, and an increase in behavioral problems, leading to enormous downstream health and economic implications. ${ }^{12,13,15}$ These numbers may grow with the recent bill passed by the United States Congress to cut US $\$ 40$ billion from the Supplemental Nutrition Assistance Program (SNAP), effectively removing millions of families from receiving food stamps.

\section{Strengths and limitations}

The primary objective of this study was to screen youth in a primary care clinic for social problems, rather than rely- ing on aggregate data or retrospective database analyses to understand the impact of social problems on health. The social problems that we captured were prospectively and individually collected. While the external generalizability of our study is limited to findings from a single center that may differ geographically from other urban centers, our results are internally valid. We used an innovate web-based computerized tool, The Online Advocate, which relies on self-reported answers to screen for social problems and, as a result, we cannot exclude the possibility of some social desirability bias. However, studies indicate that youth are more likely to respond honestly using computer screening compared to personal interview and paper questionnaires. ${ }^{40,41}$ For our outcome measure, we used self-rated health to capture the health among youth, and, while it is a robust and well-validated measure of health, it does not differentiate between types of health.

It is not uncommon for social problems to coexist; therefore, to assess the issue of collinearity among social problems, we tested the dichotomous correlation of social problems using phi correlations and reported weak correlations. Further, we also tested the correlation matrix of the regression coefficients of the multivariable model, and no significant correlation factors among social problems were found (data not shown).

\section{Conclusion}

Our study demonstrates that urban youth experience a high burden of social disparities. The presence of even one social problem adversely impacts the self-rated health of the youth. Self-rated health among youth may be lower than expected. It is important to implement screening for health-related social problems, particularly in a clinical context, to gain a deeper understanding of the complex social milieu that affects the health of youth.

\section{Acknowledgments}

The authors thank Emily Blood, Aaron Pikcilingis, Emily Krull, LaQuita McNickles, Glenn Marmon, and Elizabeth Woods for their expertise and support. Dr Kreatsoulas holds a Fulbright Scholarship and a Heart and Stroke of Ontario Research Fellowship. This study was supported by grants from Boston Children's Hospital Program for Patient Safety and Quality; Boston Children's Hospital Office of Child Advocacy; the Aerosmith Endowment Fund for Prevention and Treatment of AIDS and HIV Infections; and Boston Children's Hospital Office of Faculty Development Career Development Award, and received a Boston Children's 
Hospital Division of Adolescent Medicine's Gallagher Grant and grant 771 MC00009 from the Maternal and Child Health Bureau (Leadership in Adolescent Health Training).

\section{Author contributions}

Catherine Kreatsoulas, $\mathrm{PhD}$, was involved in study design, statistical analysis, interpretation of data, development of intellectual content, and writing and revision of the submitted manuscript and approved the final version to be published. Dr Kreatsoulas is also the overall content guarantor of the study and accepts full responsibility for the integrity of this work and/or the conduct of the study, has full access to the data, and controlled the decision to publish. Areej Hassan, $\mathrm{MD}, \mathrm{MPH}$, contributed content expertise; was involved in study design, patient recruitment, data collection, interpretation of the data, development of intellectual content; critical revision of the manuscript for important intellectual content; and approved the final version of the submitted manuscript. SV Subramanian, PhD, contributed statistical expertise; was involved in interpretation of the data; critical revision of the manuscript for important intellectual content; and approved the final version of the submitted manuscript. Eric W Fleegler, MD, MPH, conceptualized and established The Online Advocate; contributed content expertise; was involved in study design, patient recruitment, data collection, interpretation of the data, development of intellectual content; critical revision of the manuscript for important intellectual content; and approved the final version of the submitted manuscript.

\section{Disclosure}

The authors report no conflicts of interest in this work. All authors declare that we have not received any personal financial support for the submitted work, nor did any of the funding agencies have any direct involvement with the submitted work.

\section{References}

1. Sawyer SM, Afifi RA, Bearinger LH, et al. Adolescence: a foundation for future health. Lancet. 2012;379(9826):1630-1640.

2. International Youth Year Secretariat, UNV, FAO, ILO, WHO. Activities of the United Nations System in the Field of Youth. Vienna: United Nations World Congress on Youth; 1985.

3. Wilkinson RG, Marmot MG, editors. Social Determinants of Health: The Solid Facts. Vol 2. Denmark: World Health Organization; 2003.

4. Marmot M, Friel S, Bell R, Houweling TA, Taylor S; Commission on Social Determinants of Health. Closing the gap in a generation: health equity through action on the social determinants of health. Lancet. 2008;372(9650):1661-1669.

5. Viner RM, Ozer EM, Denny S, et al. Adolescence and the social determinants of health. Lancet. 2012;379(9826):1641-1652.

6. Smith GD, Hart C, Blane D, Hole D. Adverse socioeconomic conditions in childhood and cause specific adult mortality: prospective observational study. BMJ. 1998;316(7145):1631-1635.
7. Kuh D, Ben-Shlomo Y, Lynch J, Hallqvist J, Power C. Life course epidemiology. J Epidemiol Community Health. 2003;57(10): $778-783$.

8. Braveman P, Barclay C. Health disparities beginning in childhood: a life-course perspective. Pediatrics. 2009;124(Suppl 3): S163-S175.

9. DC Baltimore Research Center on Child Health Disparities Writing Group, Horn IB, Cora-Bramble D, et al. Starting early: a life-course perspective on child health disparities - research recommendations. Pediatrics. 2009;124 Suppl 3:S257-S261.

10. Johnson MK, Crosnoe R, Elder GH Jr. Insights on adolescence from a life course perspective. J Res Adolesc. 2011;21(1):273-280.

11. Shlafer R, Hergenroeder AC, Jean Emans S, et al. Adolescence as a critical stage in the MCH Life Course Model: commentary for the Leadership Education in Adolescent Health (LEAH) interdisciplinary training program projects. Matern Child Health J. 2014;18(2): $462-466$.

12. Braveman PA, Cubbin C, Egerter S, Williams DR, Pamuk E. Socioeconomic disparities in health in the United States: what the patterns tell us. Am J Public Health. 2010;100 Suppl 1: S186-S196.

13. Cook JT, Frank DA. Food security, poverty, and human development in the United States. Ann N Y Acad Sci. 2008;1136:193-209.

14. Kushel MB, Gupta R, Gee L, Haas JS. Housing instability and food insecurity as barriers to health care among low-income Americans. J Gen Intern Med. 2006;21:71-77.

15. Larson K, Russ SA, Crall JJ, Halfon N. Influence of multiple social risks on children's health. Pediatrics. 2008;121:337-344.

16. Child Health USA 2007: Hospitalization [webpage on the Internet]. Rockville, MD: US Department of Health and Human Services; 2008. Available from: http://www.mchb.hrsa.gov/chusa07/hstat/hsc/ pages/210h.html. Accessed October 28, 2013.

17. Hassan A, Blood EA, Pikcilingis A, et al. Youths' health-related social problems: concerns often overlooked during the medical visit. JAdolesc Health. 2013;53(2):265-271.

18. Wylie SA, Hassan A, Krull EG, et al. Assessing and referring adolescents' health-related social problems: qualitative evaluation of a novel web-based approach. J Telemed Telecare. 2012;18(7):392-398.

19. Bickel G, Nord M, Price C, Hamilton W, Cook J. Guide to Measuring Household Food Security. Alexandria, VA: USDA, Food and Nutrition Service, Office of Analysis, Nutrition, and Evaluation; 2000.

20. Knight JR, Sherritt L, Shrier LA, Harris S, Chang G. Validity of the CRAFFT substance abuse screening test among adolescent clinic patients. Arch Pediatr Adolesc Med. 2002;156(6):607-614.

21. Growing Up Today Study (GUTS) [homepage on the Internet]. Boston, MA: Channing Laboratory: Modern Lifestyle Future Health; 2007. Available from: http://www.gutsweb.org/. Accessed November 19, 2014.

22. United States Census Bureau. American Housing Survey (AHS). Suitland, MA United States Census Bureau; 2013. Available from: http://www.census.gov/content/census/en/programs-surveys/ahs/data. html/\#. Accessed November 19, 2014.

23. Youth Risk Behavior Survey. Malden, MA: Massachusetts Department of Elementary and Secondary Education; 2011. Available from: http:// www.cdc.gov/healthyyouth/yrbs/questionnaire_rationale.htm. Accessed December 2, 2014.

24. Harris KM, Halpern CT, Whitsel E, Hussey J, Tabor J, Entzel P, Udry JR. The National Longitudinal Study of Adolescent to Adult Health: Research Design. Add Health; 2009. Available from: http://www.cpc. unc.edu/projects/addhealth/design. Accessed February 14, 2015.

25. Behavioral Risk Factor Surveillance System [webpage on the Internet]. Atlanta, GA: Centers for Disease Control and Prevention [updated September 2, 2014]. Available from: http://www.cdc.gov/brfss/. Accessed November 19, 2014.

26. Kahn RS, Wise PH, Finkelstein JA, Bernstein HH, Lowe JA, Homer CJ. The scope of unmet maternal health needs in pediatric settings. Pediatrics. 1999;103(3):576-581. 
27. Benyamini Y. Why does self-rated health predict mortality? An update on current knowledge and a research agenda for psychologists. Psychol Health. 2011;26(11):1407-1413.

28. Idler EL, Benyamini Y. Self-rated health and mortality: a review of twenty-seven community studies. J Health Soc Behav. 1997;38(1): 21-37.

29. Bauldry S, Shanahan MJ, Boardman JD, Miech RA, Macmillan R. A life course model of self-rated health through adolescence and young adulthood. Soc Sci Med. 2012;75(7):1311-1320.

30. Boardman JD. Self-rated health among US adolescents. J Adolesc Health. 2006;38(4):401-408.

31. Hoyert DL, Xu JQ. Deaths: Preliminary data for 2011. National vital statistics reports; vol 61 no 6. Hyattsville, MD: National Center for Health Statistics; 2012. Available from: www.cdc.gov/nchs/data/nvsr/ nvsr61/nvsr61_06.pdf. Accessed November 19, 2014.

32. Newacheck PW, Wong ST, Galbraith AA, Hung YY. Adolescent health care expenditures: a descriptive profile. J Adolesc Health. 2003;32: 3-11.

33. Simpson L, Owens PL, Zodet MW, et al. Health care for children and youth in the United States: annual report on patterns of coverage, utilization, quality, and expenditures by income. Ambul Pediatr. 2005;5:6-44.

34. Garg A, Butz AM, Dworkin PH, Lewis RA, Thompson RE, Serwint JR. Improving the management of family psychosocial problems at low-income children's well-child care visits: the WE CARE Project. Pediatrics. 2007;120:547-558.
35. Lui CK, Chung PJ, Wallace SP, Aneshensel CS. Social status attainment during the transition to adulthood. J Youth Adolesc. 2014;43(7): 1134-1150.

36. Galobardes B, Lynch JW, Davey Smith G. Childhood socioeconomic circumstances and cause-specific mortality in adulthood: systematic review and interpretation. Epidemiol Rev. 2004;26:7-21.

37. Mulye TP, Park MJ, Nelson CD, Adams SH, Irwin CE Jr, Brindis CD. Trends in adolescent and young adult health in the United States. J Adolesc Health. 2009;45(1):8-24.

38. Park MJ, Paul Mulye T, Adams SH, Brindis CD, Irwin CE Jr. The health status of young adults in the United States. J Adolesc Health. 2006;39(3):305-317.

39. Kirzinger W, Cohen R, Gindi R. Trends in Insurance Coverage and Source of Private Coverage Among Young Adults Aged 19-25: United States, 2008-2012. Hyattsville, MD: National Center for Health Statistics; 2013. Available from: http://www.cdc.gov/nchs/data/ databriefs/db137.pdf. Accessed November 19, 2014.

40. Mackenzie SL, Kurth AE, Spielberg F, et al. Patient and staff perspectives on the use of a computer counseling tool for HIV and sexually transmitted infection risk reduction. J Adolesc Health. 2007; 40(6):572. e9-e16.

41. Winters KC, Stinchfield RD, Henly GA, Schwartz RH. Validity of adolescent self-report of alcohol and other drug involvement. Int $J$ Addict. 1990;25(11A):1379-1395. 


\section{Supplementary material}

Table SI Composition of problems that compose social disparity domains

\begin{tabular}{ll}
\hline Domain & Qualifying problem(s) \\
\hline Education & - Unmet learning disability \\
- Dropped out of high school & - No health insurance \\
Health care access & - Unable to receive prescriptions \\
& - Unable to receive medical care \\
- Unmet dental needs & - Out of work and trying to find a job \\
Income security & - Positive CRAFFT score' \\
Substance use & - Tobacco use \\
Food insecurity & - Hungry \\
Housing & - Homeless \\
& - Utilities shut off \\
Interpersonal violence & - Physical, verbal, or sexual abuse in \\
& the past I2 months \\
\hline
\end{tabular}

Abbreviation: CRAFFT, Car, Relax, Alone, Forget, Friends, Trouble.

\section{Reference}

1. The Center for Adolescent Substance Abuse Research (CeASAR) [homepage on the Internet]. Boston, MA: Children's Hospital; 2009. Available from: http://www.ceasar-boston.org/CRAFFT/. Accessed November 19, 2014.

\section{Publish your work in this journal}

Adolescent Health, Medicine and Therapeutics is an international, peer-reviewed, open access journal focusing on health, pathology, and treatment issues specific to the adolescent age group. All aspects of health maintenance, preventative measures and disease treatment interventions are addressed within the journal and practitioners from all disciplines are invited to submit their work as well as healthcare researchers and patient support groups.. The manuscript management system is completely online and includes a very quick and fair peerreview system. Visit http://www.dovepress.com/testimonials.php to read real quotes from published authors.

Submit your manuscript here: http://www.dovepress.com/adolescent-health-medicine-and-therapeutics-journal 